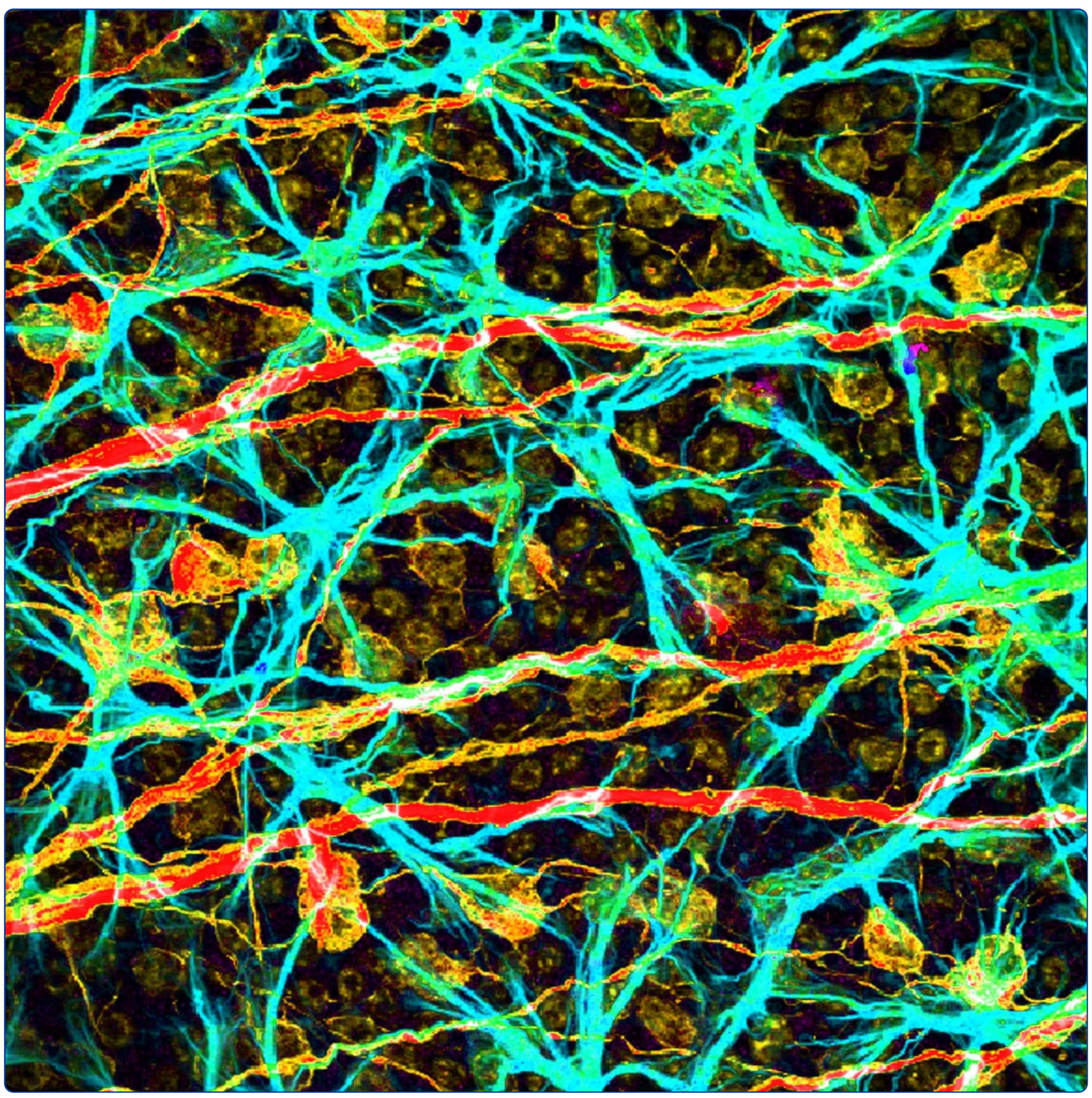

\title{
Brimonidine prevents axonal and somatic degeneration of retinal ganglion cell neurons
}

Lambert et al. 


\title{
Brimonidine prevents axonal and somatic degeneration of retinal ganglion cell neurons
}

\author{
Wendi S Lambert', Lupe Ruiz', Samuel D Crish¹, Larry A Wheeler², David J Calkins ${ }^{*}$
}

\begin{abstract}
Background: Brimonidine is a common drug for lowering ocular pressure and may directly protect retinal ganglion cells in glaucoma. The disease involves early loss of retinal ganglion cell transport to brain targets followed by axonal and somatic degeneration. We examined whether brimonidine preserves ganglion cell axonal transport and abates degeneration in rats with elevated ocular pressure induced by laser cauterization of the episcleral veins.

Results: Ocular pressure was elevated unilaterally by $90 \%$ for a period of 8 weeks post- cauterization. During this time, brimonidine $(1 \mathrm{mg} / \mathrm{kg} / \mathrm{day})$ or vehicle (phosphate-buffered saline) was delivered systemically and continuously via subcutaneous pump. Animals received bilateral intravitreal injections of fluorescent cholera toxin subunit $\beta$ (CTB) two days before sacrifice to assess anterograde transport. In retinas from the vehicle group, elevated pressure induced a $44 \%$ decrease in the fraction of ganglion cells with intact uptake of CTB and a 14-42\% reduction in the number of immuno-labelled ganglion cell bodies, with the worst loss occurring nasally. Elevated pressure also caused a 33\% loss of ganglion cell axons in vehicle optic nerves and a 70\% decrease in CTB transport to the superior colliculus. Each of these components of ganglion cell degeneration was either prevented or significantly reduced in the brimonidine treatment group.

Conclusions: Continuous and systemic treatment with brimonidine by subcutaneous injection significantly improved retinal ganglion cell survival with exposure to elevated ocular pressure. This effect was most striking in the nasal region of the retina. Brimonidine treatment also preserved ganglion cell axon morphology, sampling density and total number in the optic nerve with elevated pressure. Consistent with improved outcome in the optic projection, brimonidine also significantly reduced the deficits in axonal transport to the superior colliculus associated with elevated ocular pressure. As transport deficits to and from retinal ganglion cell projection targets in the brain are relevant to the progression of glaucoma, the ability of brimonidine to preserve optic nerve axons and active transport suggests its neuroprotective effects are relevant not only at the cell body, but throughout the entire optic projection.
\end{abstract}

\section{Background}

Glaucoma is a chronic disease that causes vision loss through the degeneration of retinal ganglion cell (RGC) neurons and their axons in the optic nerve $[1,2]$. While age is an important risk factor, the only modifiable risk factor and sole target for clinical intervention is elevated intraocular pressure (IOP) or ocular hypertension (OHT) [3]. Lowering IOP generally slows progression in glaucoma [3], but does not necessarily stop degeneration [4].

\footnotetext{
* Correspondence: david.j.calkins@vanderbilt.edu

'The Vanderbilt Eye Institute, Vanderbilt University Medical Center, Nashville, TN 37205, USA

Full list of author information is available at the end of the article
}

Thus, there is great interest in identifying neuroprotective agents as potential therapies $[5,6]$.

Brimonidine (BMD; UK14304, Alphagan) is a nonselective $\alpha 2$-adrenergic receptor agonist currently used as a treatment to lower IOP in glaucoma. An effect of BMD is to decrease aqueous humor production by inhibition of adenylate cyclase inhibition, which lowers cAMP levels [7]. The drug also increases uveoscleral outflow due to prostaglandin release and/or ciliary muscle relaxation [8]. Independent of its IOP-lowering properties, BMD is neuroprotective for RGCs in various injury models [9-13]. Potential mechanisms underlying these effects include the inhibition of glutamate release, 
regulation of calcium influx in the inner retina, modulation of NMDA receptor signalling in RGCs, and upregulation of trophic factor expression [14-16]. Because of its dual action to lower IOP and perhaps protect against neuronal injury, BMD may hold promise in the treatment of glaucoma and other optic neuropathies [17].

Following acute ischemic injury, BMD preserves axonal transport along RGC axons from the retina to the superior colliculus [18]. This is intriguing in the context of glaucoma, as recent evidence indicates axon-specific mechanisms play an early role in the pathology of the disease [19-21]. Here we investigated whether systemic treatment with BMD by continuous subcutaneous injection improves axon survival in the optic nerve and anterograde transport to the colliculus with acute OHT.

\section{Results}

Systemic brimonidine treatment does not affect IOP

We induced OHT unilaterally in rats using laser photocoagulation of episcleral and limbal veins as described below. Systemic treatment with either BMD (1 mg/kg/day) or vehicle (phosphate-buffered saline, PBS) began at the time of initial IOP elevation and continued for the 8 week period of elevation. We chose this dosing regimen based on previous experiments examining the effects of systemic BMD on RGC survival with elevated ocular pressure [11]. Eyes without laser injury (naïve, vehicle control, BMD control) had an average IOP of $15.5 \pm 0.1 \mathrm{mmHg}$ that did not differ between groups $(\mathrm{p}=0.59$; Figure 1$)$. One week following induction of OHT, IOP reached a peak of $32.3 \pm$ $0.1 \mathrm{mmHg}$ in both vehicle and BMD OHT eyes $(\mathrm{p}=0.96)$. Thereafter IOP remained elevated by $90 \pm 6 \%$ in the vehicle group and by $91 \pm 7 \%$ in the BMD group compared to the control eye ( $\mathrm{p}=0.85)$; neither changed significantly over the experimental period ( $p \geq 0.2)$. Thus, systemic delivery of BMD by subcutaneous osmotic pump had no effect on IOP (Figure 1).

\section{Brimonidine prevents loss of RGCs with OHT}

We compared the localization of CTB and phosphorylated heavy-chain neurofilaments (SMI31) in whole-mounted retinas from naïve, vehicle and BMD rats (Figure 2). In naïve, vehicle and BMD control retinas, nearly every RGC labelled by SMI31 also demonstrated intact CTB uptake (Figure 2A-D,G). Vehicle OHT retinas contained far fewer $\mathrm{CTB}+$ and SMI31 + RGCs (Figure 2E,F). In these retinas, RGC axons also contained less CTB, indicative of diminished active uptake and transport, and more intense concentration of SMI31, suggesting accumulation. Vehicle OHT retinas also showed obvious axonal dystrophy, swelling of RGC somas, and accumulation of SMI31 in RGC dendrites. In contrast, OHT retinas from BMD treated rats appeared similar to naïve and control retinas with respect to SMI31 and CTB localization (Figure 2H,I). Few, if any, dystrophic axons or swollen RGCs were observed in these retinas.

Next we quantified the number of SMI31+ and CTB+ RGCs in each group. For simplicity, we represent the RGC counts as the ratio of the right to left retina for the naïve group and as the ratio of OHT to control retina for the vehicle and BMD groups (Figure 3). As expected, for the naïve group the ratios for both SMI31 and CTB counts were identical to one, indicating no difference between the right and left eyes $(p \geq 0.22)$. In the

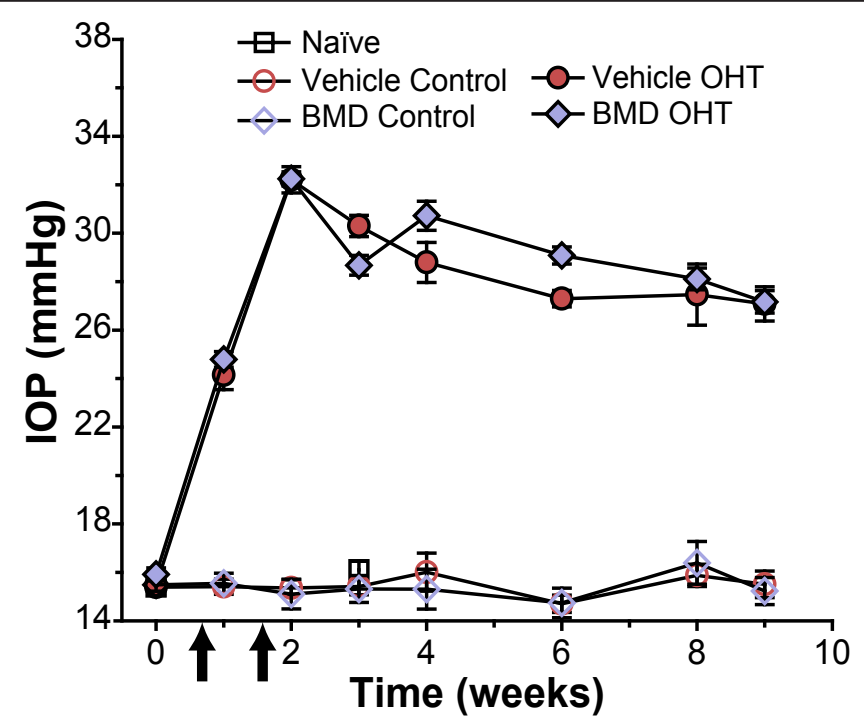

Figure 1 Systemic BMD does not affect IOP. Ocular pressure in $\mathrm{mmHg}$ as measured using TonoLab following laser photocoagulation of episcleral veins at two time points (arrows). Systemic BMD (1 mg/kg/day) delivered via subcutaneous osmotic pump did not affect IOP for control or OHT eyes compared to vehicle treatment ( $p \geq 0.6$; mean \pm SEM; $n=16$ eyes per group). 

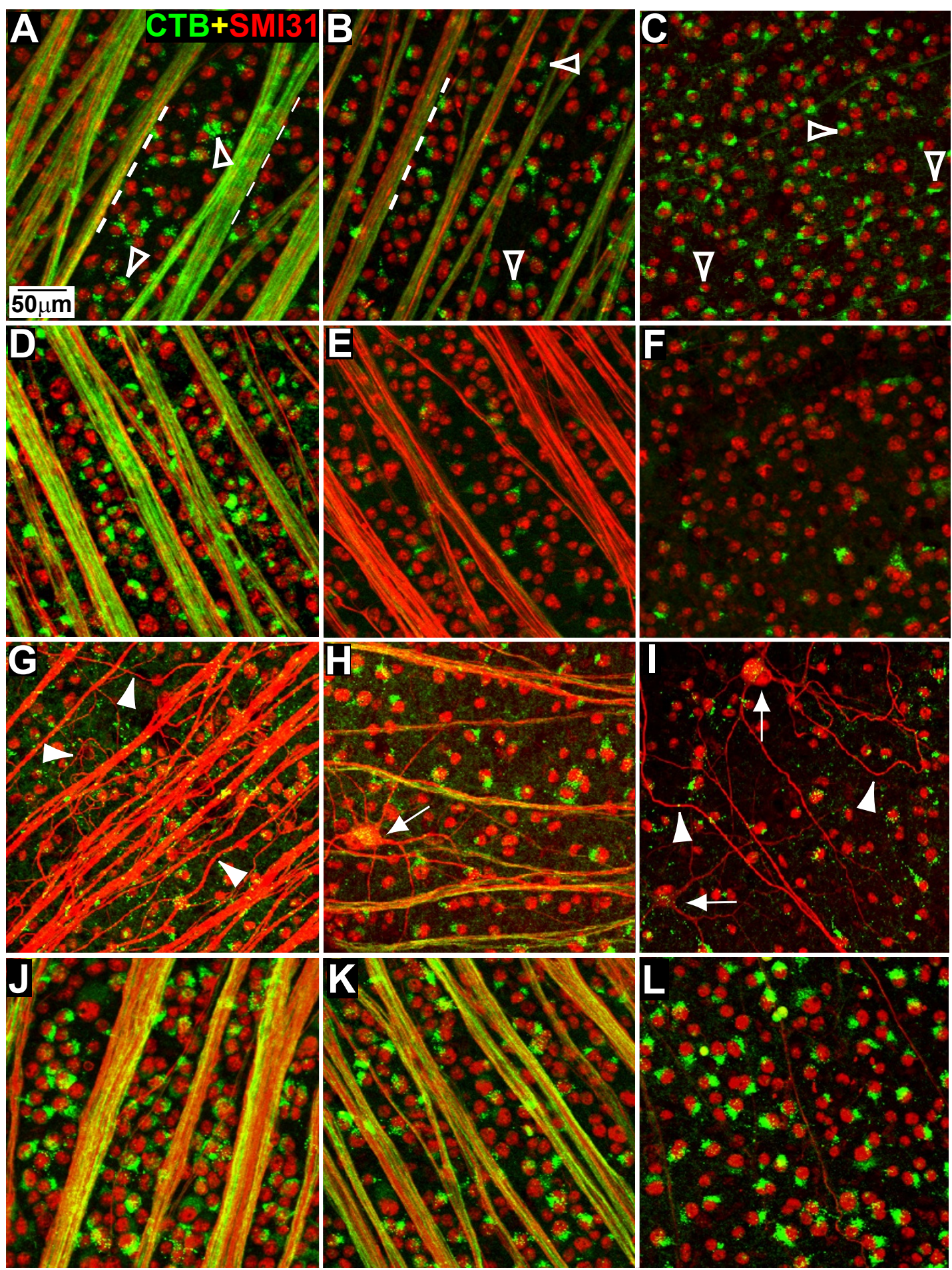

Figure 2 BMD preserves RGC morphology in retinas exposed to OHT. (A-C) Representative confocal images of whole-mounted naïve rat retina demonstrating co-localization of CTB (green) with phosphorylated heavy-chain neurofilament (SMI31; red) in RGC axons (dashed lines) and somas (open arrowheads). Similar co-localization was observed in vehicle (D) and BMD (J) control retinas. Vehicle OHT retinas (E-I) demonstrated fewer CTB + RGC somas and axons, dystrophic axons (arrowheads), and swollen RGCs with dendrites accumulating SMI31 (arrows). In BMD OHT retinas $(K, L)$, co-localization of CTB and SMI31 was similar to that in naïve and control retinas. Distance from optic disc is $1 \mathrm{~mm}(A, D, E, G, J, K)$, $2 \mathrm{~mm}(B, H, I)$, or $4 \mathrm{~mm}(C, F, L)$. 


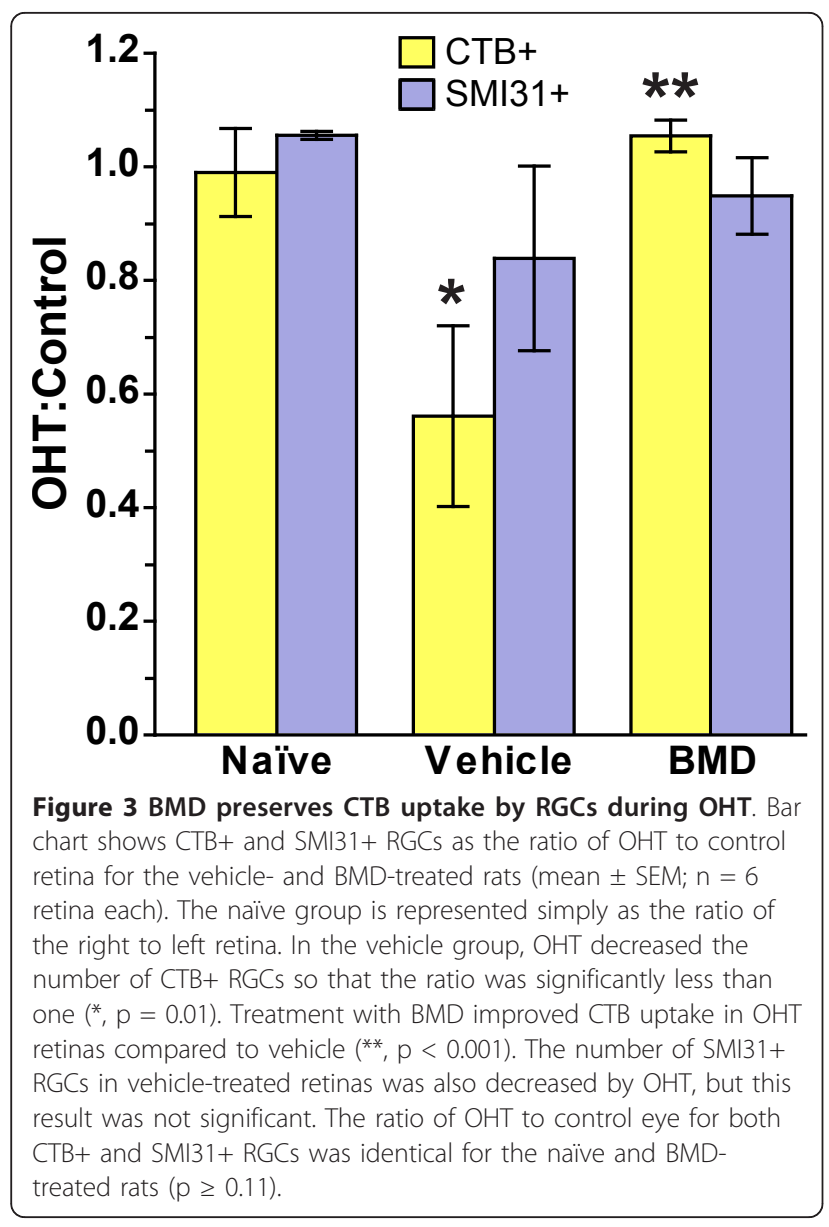

vehicle group, the number of CTB + RGCs in the OHT retina was only $56 \%$ that of the control retina, which was a significant reduction $(\mathrm{p}=0.01)$. BMD completely prevented this decrease: the ratio of the OHT to control eye was the same as the naïve group $(\mathrm{p}=0.42)$. Compared to the vehicle group, this was a dramatic improvement of $200 \%$ ( $p<0.001)$. In terms of SMI31+ RGCs, in the vehicle group, the number in the OHT retina was $84 \%$ that of the control retina, which was not significant $(p=0.26)$. In the BMD group, the number of SMI31+ RGCs was the same for both eyes and not distinguishable from naïve $(\mathrm{p}=0.11)$.

Figure 3 indicates a large variability for the vehicle group in terms of the effects of OHT on RGC number, with standard errors $25-30 \%$ of the mean for both $\mathrm{CTB}+$ and SMI31+ cells. To determine if the variability was retinotopic, as in other models [22-25], we quantified SMI31+ RGCs along the midline of each retinal quadrant as a function of eccentricity from the optic disc (Figure 4). In naïve retinas RGC density ranged from 2,900 to $5,400 \mathrm{RGCs} / \mathrm{mm}^{2}$ with a mean across quadrants of $4000 \pm 170 \mathrm{RGCs} / \mathrm{mm}^{2}$. This is comparable to published values for RGC density for this species
$[25,26]$. The number of labelled RGCs in vehicle control retinas was slightly higher for the inferior and nasal quadrants $\left(4600 \pm 440 \mathrm{RGCs} / \mathrm{mm}^{2}\right)$, but this difference was not significant compared to naïve $(\mathrm{p} \geq 0.1)$. Across quadrants, we found no difference in RGC density between vehicle control $\left(4200 \pm 330 \mathrm{RGCs} / \mathrm{mm}^{2}\right)$ and BMD control $\left(4025 \pm 174 \mathrm{RGCs} / \mathrm{mm}^{2}\right)$ retinas $(\mathrm{p} \geq 0.2)$, so these were combined in the comparisons that follow (Figure 4).

For all retinal quadrants, the density of SMI31+ RGCs in the control retinas peaked within 1-2 $\mathrm{mm}$ of the optic nerve head $\left(3,400\right.$ to $\left.5,400 \mathrm{RGCs} / \mathrm{mm}^{2}\right)$ and decreased slightly (17 to $18 \%$ ) at $4 \mathrm{~mm}$ out (Figure 4 ). In the superior retina of the vehicle group, OHT decreased RGC density by 15 to $17 \%$ across eccentricity compared to control eyes. RGC density in the same sector for the BMD OHT retinas was $14-24 \%$ higher than the vehicle OHT retinas; neither group was significant different than the corresponding control eye $(\mathrm{p} \geq 0.2)$. In the inferior quadrant of vehicle retinas, OHT decreased RGC density 14 - 25\% compared to control retinas with significant reductions of $25 \%$ and $23 \%$ observed at 1 and $2 \mathrm{~mm}$ eccentric, respectively ( $\mathrm{p} \leq$ $0.05)$. For the BMD group in this quadrant, RGC density did not change with OHT compared to control ( $\mathrm{p} \geq$ 0.25). In the temporal quadrant for vehicle retinas, OHT decreased RGC density 14 - 27\% compared to control; at $4 \mathrm{~mm}$ eccentricity this decrease (27\%) was significant $(\mathrm{p}=0.04)$. For the BMD group in this quadrant, RGC density in OHT retinas was similar to control retinas at all eccentricities $(\mathrm{p} \geq 0.2)$. The $31 \%$ improvement in RGC density compared to vehicle OHT retinas was significant at $1 \mathrm{~mm}$ from the optic disc $(\mathrm{p}=0.05)$. Finally, RGC loss in vehicle OHT eyes was most dramatic in the nasal retina, where RGC density decreased at every location. Decreased density compared to control retinas ranged from $42 \%$ nearest the optic disc to $26 \%$ at $4 \mathrm{~mm}$ eccentricity ( $\mathrm{p} \leq 0.02)$. BMD treatment afforded partial rescue of RGCs in this quadrant, with significant increases of $30-42 \%$ at $1-3 \mathrm{~mm}$ eccentricity compared to vehicle OHT retinas $(\mathrm{p} \leq 0.005)$. However, only at $1 \mathrm{~mm}$ was RGC density in the BMD OHT group comparable to the control group $(\mathrm{p}=0.09)$.

\section{Brimonidine protects RGC axons}

We compared RGC axon morphology and survival after OHT in cross sections of vehicle- and BMD-treated optic nerves. Vehicle OHT nerves (Figure 5A and 5B) displayed degenerating axon profiles and gliotic scarring compared to vehicle control nerves (Figure $5 \mathrm{C})$. In contrast, BMD OHT nerves were similar in appearance to control nerves, with few if any degenerating profiles (Figure 5D). We quantified axon density (axons $/ \mathrm{mm}^{2}$ ) and total number of axons for each 


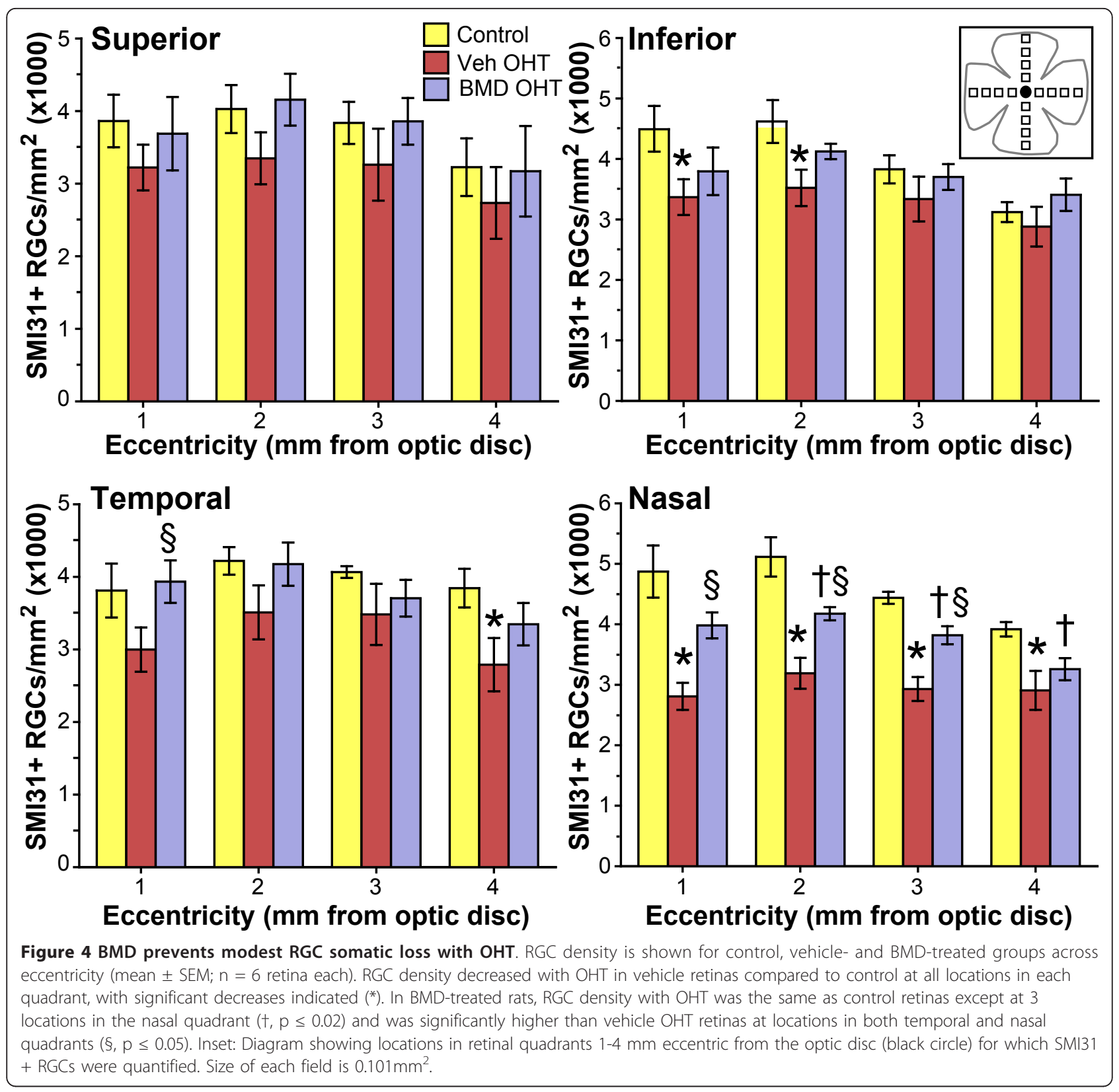

group. Once again for simplicity, these are shown as the ratio of the right to left nerve for the naïve group and as the ratio of the OHT to control nerve for the vehicle and BMD treated groups (Figure 5E). As expected, both ratios were identical to one for the naïve, indicating no difference between the two eyes. For the vehicle group, axon density was $25 \%$ less and the number of axons 33\% less in the OHT nerve compared to control, yielding ratio that differed significantly from one $(\mathrm{p} \leq 0.03)$. Conversely, for BMDtreated animals both axon density and axon number were similar between the OHT and control nerves, yielding ratios identical to those for naïve rats $(p \geq$ $0.3)$. Both measures were considerably improved compared to vehicle-treated rats $(\mathrm{p}=0.011)$.

Brimonidine substantially restores anterograde transport We compared anterograde transport of CTB from the retina to the superior colliculus in naïve, vehicle-, and BMD-treated animals (Figure 6). Complete CTB labelling of the RGC-recipient zone was observed in colliculi from naïve eyes (Figure 6A) and in colliculi from control eyes in the vehicle group (Figure 6B). The corresponding retinotopic maps for these colliculi were reconstructed from 


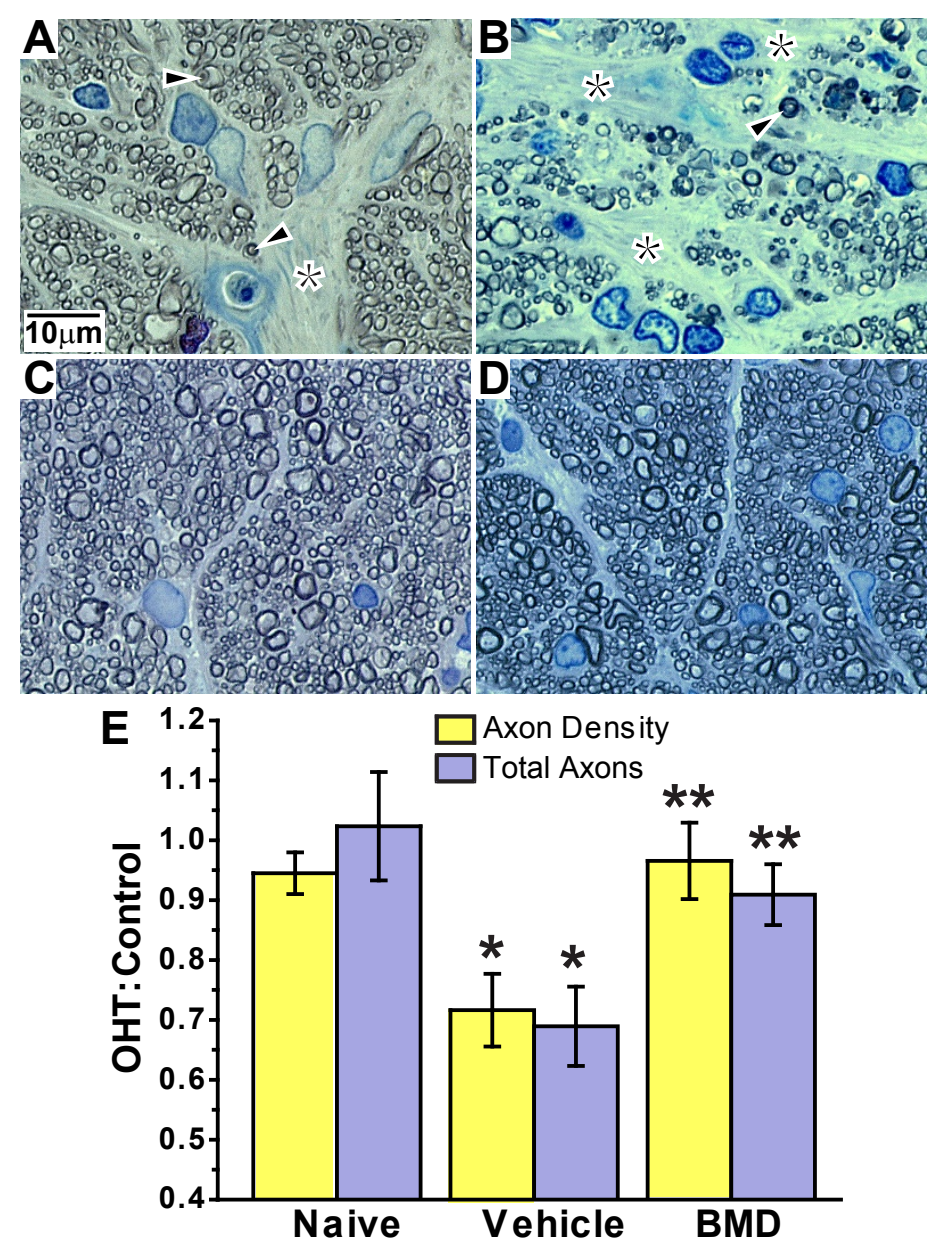

Figure 5 BMD preserves RGC axon morphology, density and total number following OHT. High-magnification light photomicrographs demonstrating degenerating axon profiles (arrowheads) and gliotic scars (asterisks) in cross-sections of vehicle OHT optic nerves (A and B). Like vehicle control nerve (C), nerves from BMD OHT rats (D) had significantly fewer degenerating profiles. (E) Axon density and total axon number expressed as the ratio of $\mathrm{OHT}$ to control nerve for vehicle and BMD groups; naïve group is the ratio of the right to left nerve (mean \pm SD; $n=$ 16 each). Density and axon number decreased in vehicle treated rats so that the ratio for each differed significantly from one $\left(^{*}, p \leq 0.02\right)$. BMD treatment improved both outcome measures compared to vehicle $\left(^{* *}, p=0.011\right)$.

serial sections. These showed complete representations of CTB signal except for the retinal optic disc gap, which contains no RGCs. Complete labelling of colliculi from control eyes of the BMD-treated group was also observed (data not shown). In contrast, colliculi from vehicle OHT eyes demonstrated severe deficits in CTB signal, ranging from a retinotopic hemifield (Figure $6 \mathrm{C}$, left) to nearly complete loss (Figure 6C, right). OHT in the BMD group had far less affect on CTB transport to the colliculus, yielding retinotopic representations ranging from complete (Figure 6D, left) to mild deficits (Figure 6D, right). When quantified as the fraction of intact retinotopic map (Figure 6E), as expected CTB transport to the colliculus was similar for the two eyes of the naive group ( $p \geq 0.18$ ). Similarly, there was no difference in intact transport between naive colliculi and colliculi from the control eyes for both the vehicle and BMD groups ( $p \geq 0.49$ ).
With OHT for vehicle rats, the average deficit in CTB transport was $71.8 \pm 6.4 \%$. With a range of intact transport of only $2-58 \%$, this represented a significant reduction compared to control eye transport $(93.4 \pm 3.0 \%$ intact, $\mathrm{p}=0.001$ ). For the BMD group, OHT-induced deficits were far less, with an average deficit of $36.9 \pm$ $7.8 \%$ and a range of intact transport of $36-97 \%$. While this range was decreased compared to control eye colliculi for the group $(97.0 \pm 1.5 \%$ intact, $\mathrm{p}=0.004)$, BMD treatment improved transport by $124 \%$ compared to the OHT colliculi for vehicle animals $(\mathrm{p}=0.002)$.

We found earlier that the most dramatic reduction in RGC density in the retina was in the nasal quadrant (Figure 4). In other animal models of glaucoma, loss of anterograde transport to the superior colliculus is also spatially-specific, filling in one retinal sector completely before affecting another [21]. We found that typically, 

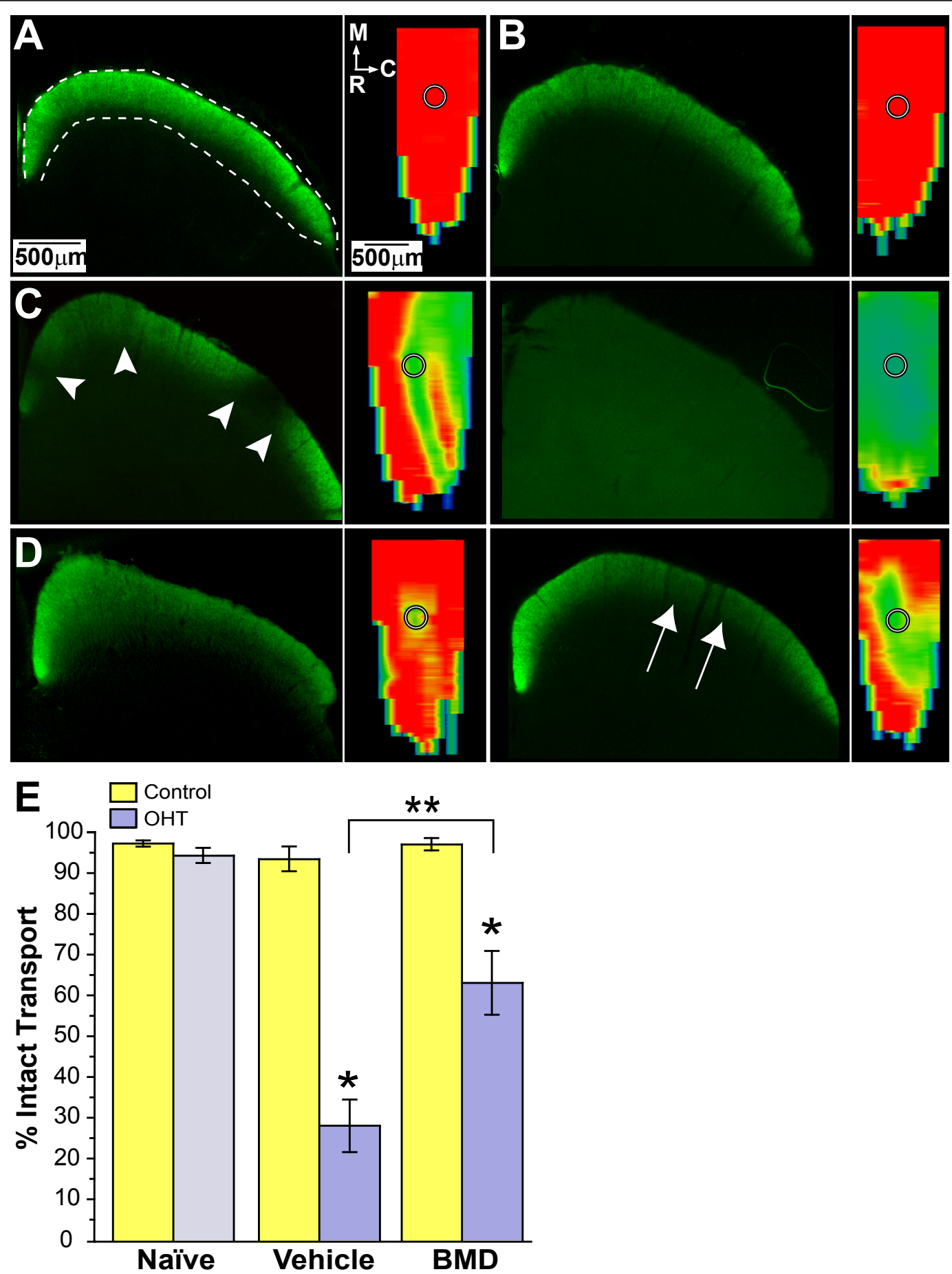

Figure 6 BMD partially preserves anterograde transport following acute IOP elevation. (A) Representative cross-section through medial superficial superior colliculus (left, outlined) from naive rat showing normal RGC anterograde transport of CTB (green). Corresponding retinotopic map reconstructed from serial cross-sections through the colliculus (right) shows representation of optic disc gap (circle). Colorimetric scale indicates levels of transport from 100\% (red) to 50\% (green) to 0\% (blue). (B) Comparable colliculus section (left) and retinotopic map (right) corresponding to vehicle control eye also shows intact transport. (C) Sections of colliculus corresponding to OHT eye in vehicle group show deficits ranging from sectorial (arrowheads on left) to complete loss (right). Corresponding retinotopic maps were 58\% (left) and 7\% (right) intact, respectively. (D) Colliculus from OHT eye in BMD-treated rats show range of rescued transport from complete (left) to modest (85\% intact, right). (E) CTB transport in colliculus calculated as the fraction of the retinotopic map with $\geq 70 \%$ maximum signal for three groups (mean \pm SEM; $n=11$ each). Naiive group represents transport to the left and right colliculi. OHT decreased CTB transport $70 \%$ in vehicle-treated rats $\left({ }^{*}, p=0.001\right)$ but only 35\% in BMD-treated animals (*, $\mathrm{p}=0.004)$. BMD significantly improved transport with OHT when compared to vehicle eyes $(* *, p=0.002)$. 
transport deficits due to $\mathrm{OHT}$ in the vehicle group were quite severe (see above), so spatial progression was difficult to assess. However, when we transformed the retinotopic maps of colliculus transport into retinal quadrant and eccentricity coordinates following Siminoff et al. [27] and Drager and Hubel [28], we found hints that deficits due to OHT begin nasally. Compared to naïve or control (Figure 7A), for vehicle colliculi, moderate OHT-induced transport deficits ( $42 \%$ to $57 \%$ loss) filled in from the nasal retina to the optic disk representation (Figure 7B). In vehicle colliculi with severely affected transport $(>80 \%$ loss), deficits continued to spread from the nasal representation to the optic disc and into other retinal sectors. Even the more modest transport deficits from OHT eyes in the BMD-treated group appeared to follow the same geographic progression (Figure 7D).

\section{Discussion}

In this study, we quantified how systemic delivery of BMD via subcutaneous osmotic pump protected RGCs challenged by elevated IOP in a rat model of OHT. In the absence of treatment, OHT for 8 weeks induced pathology at several levels. In the vehicle group, the worst OHT-related outcome was $70 \%$ depletion in transport of CTB to the superior colliculus (Figure 6). This deficit cannot be accounted for entirely by loss of active uptake of CTB by RGCs in the retina, which was reduced by only $44 \%$ (Figure 3 ). Depletion of transport was followed by a $33 \%$ loss of axons in the optic nerve (Figure 5) and finally by an average decrease in RGC somatic density of about $16 \%$ as measured by SMI31 labelling (Figure 4). In the retina, OHT was also associated with severely dystrophic axons, swollen RGC somas, and the accumulation of phosphorylated neurofilaments in dendrites (Figure 2).

These results support an OHT-induced progression in which a functional deficit precedes structural pathology. Loss of active uptake and transport of CTB was far worse than axon loss in the optic nerve, which in turn was worse than RGC somatic drop-out in the retina. This progression is similar to that described in the DBA2J mouse model of glaucoma [20,21,23]. Interestingly, RGC somatic loss as measured by SMI31 labelling was not uniform. Rather, it was worst in the nasal retina, where OHT decreased RGC density 26 to $42 \%$ across eccentricities (Figure 4). This spatial progression too is consistent with the sectorial pattern of RGC pathology observed in other glaucoma models $[22,23,29,30]$. Though axonal transport to the superior colliculus was severely affected by OHT, our retinotopic maps also hint of sectorial progression (Figure 7; [21]).

Although there is some earlier evidence that BMD can preserve optic nerve axons and RGC axonal transport after acute injury $[9,31,32]$, previous studies of BMD's effect in glaucoma models have focused on retinal outcomes $[11,12,16,33,34]$. Following episcleral vein cautery, BMD delivered via intraperitoneal injection prevented OHT-induced loss of RGC cell bodies labelled by retrograde transport of FluoroGold from the colliculus [12,33]. In studies similar to ours in which OHT was induced by laser photocoagulation of episcleral and limbal veins for 3 weeks, BMD delivered by subcutaneous pump also improved the number of RGCs labeled retrogradely $[11,16,34]$. Our results are in agreement with these previous studies in that systemic BMD delivery increased RGC cell body survival (Figure 3 and Figure 4), even for our much longer period of OHT. However, given recent evidence that RGC somatic loss occurs late in disease progression [20], we examined axonal transport to the colliculus and axon survival in the nerve, both of which are challenged much earlier [21].

We found that systemic BMD treatment via subcutaneous delivery ameliorated the effects of OHT on each of our outcome measures. In the retina, BMD preserved RGC axonal and dendritic morphology (Figure 2), restored CTB uptake (Figure 3), and increased the number of SMI31+ RGCs, especially in the nasal retina where OHT-induced loss was greatest (Figure 4). In the optic nerve, BMD restored the axonal population to control levels as well (Figure 5). Finally, BMD improved anterograde axonal transport to the SC by $124 \%$ (Figure 6). As transport deficits to and from RGC targets are relevant to the progression of glaucoma [20,21], the ability of BMD to preserve optic nerve axons and axonal transport suggest its neuroprotective effects are pertinent not only at RGC soma, but throughout the entire retinal projection.

BMD is a non-subtype-selective $\alpha 2$-adrenergic receptor agonist. All three $\alpha 2$ receptors subtypes are expressed in the retina, with expression of $\alpha 2 \mathrm{~A}$ and $\alpha 2 \mathrm{~B}$ receptors by RGCs and $\alpha 2 B$ receptors by glia $[35,36]$. Activation of $\alpha 2$ receptors within the retina elicits many responses including reduced glial activation [11,37], decreased oxidative stress $[38,39]$ and protection against apoptosis [40-42]. In addition, BMD may protect RGCs by regulating intracellular $\mathrm{Ca}^{2+}$ levels and glutamate availability within the retina $[16,43]$. Excess glutamate can result in RGC apoptosis via overstimulation of NMDA receptors and subsequent increases in intracellular $\mathrm{Ca}^{2+}$. Stimulation of $\alpha 2$ receptors also results in the activation of the phosphatidylinositol 3 kinase (PI3K) pathway $[44,45]$. Activation of the PI3K pathway promotes RGC survival after various injuries $[46,47]$, perhaps by altering gene expression [48-50], regulating protein activity $[51,52]$, or by affecting cellular metabolism $[53,54]$. These and other responses make $\alpha 2$ agonists like BMD ideal neuroprotective agents within the retina.

A potential mechanism underling the neuroprotective effect of BMD on RGC axons involves the inactivation of glycogen synthase kinase-3 (GSK3) via the PI3K pathway. 


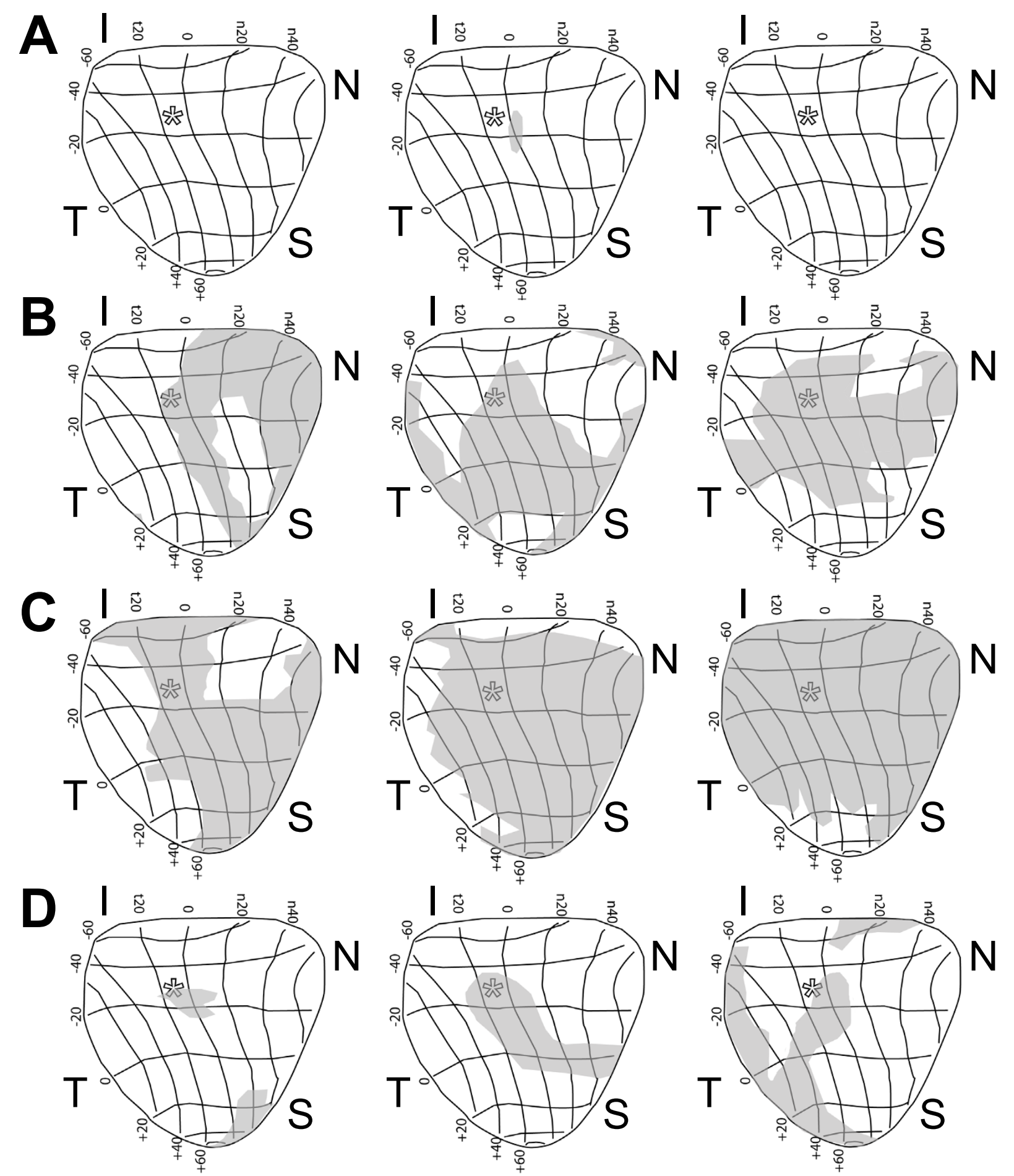

Figure 7 Deficits in anterograde transport begin in the nasal retina. Retinotopic maps of CTB transport transformed into retinal quadrant and eccentricity coordinates following Siminoff et al. (1966) [27] and Drager and Hubel (1976) [28]. (A) Colliculus maps for naïve (left), vehiclegroup control (middle) and BMD-group control (right) eyes are complete (98-99\%) and show location of optic disk (*). (B) Moderate transport deficits (shaded regions) in colliculi from vehicle OHT eyes with 58\%, 50\% and $43 \%$ intact transport (left to right respectively) appear to spread from the nasal retinal representation to the optic disk. (C) Moderate to severe transport deficits in vehicle OHT colliculi with 39\%, 19\% and 2\% intact transport (left to right respectively) continue to spread from the optic disk to other retinal quadrants. (D) BMD treatment ameliorates most transport deficits ( $96 \%$ intact, left) but the same spatial pattern of progression applies for even modest deficits ( $84 \%$ and $80 \%$ intact, middle and right respectively). Abbreviations: I, N, S, T indicate inferior, nasal, superior and temporal quadrants of the retina, respectively. 
GSK3 is a constitutively active and ubiquitous kinase. In neurons, GSK3 phosphorylates microtubule-associated protein $1 \mathrm{~B}$, resulting in loss of stable microtubules [55]. GSK3 also phosphorylates collapsin response mediator protein-2, which promotes microtubule assembly and links tubulin heterodimers to kinesin-1 to regulate protein transport to distal regions of axons [56-58]. Also, GSK3 activation is implicated in hyper-phosphorylation of axon cytoskeletal proteins, including neurofilaments $[59,60]$. Interestingly, GSK3 can be inactivated by downstream kinases in the PI3K pathway [61-63], thus providing a possible link between $\alpha 2$ receptor activation and preservation of the axonal cytoskeleton. Activation of the PI3K pathway via treatment with BMD could counteract these changes, consequently preserving both axonal transport and structure. Since BMD applied either topically to the cornea or via systemic injection reaches the posterior segment in appreciable concentrations [64], its use could represent a viable intervention for combating early axon deficits in glaucoma.

\section{Conclusions}

Ocular hypertension in rats resulted in a substantial decline in RGC axonal transport to the superior colliculus, diminished axon survival in the optic nerve, and reduced RGC density in the retina, especially in the nasal quadrant. Systemic treatment with BMD significantly improved axonal transport and survival and either prevented or decreased loss of RGC density across retinal quadrants. As transport deficits to and from RGC targets are relevant to the progression of glaucoma, the ability of BMD to preserve optic nerve axons and axonal transport suggest its neuroprotective effects are pertinent not only at the cell body, but throughout the entire retinal projection as well.

\section{Methods}

\section{IOP elevation and brimonidine delivery}

Unilateral IOP elevation in male Sprague-Dawley rats (weight range, 350 - $400 \mathrm{~g}$ ) was achieved by laser photocoagulation of episcleral and limbal veins as described previously [11]. Rats were anesthetized with a mixture of ketamine $(50 \mathrm{mg} / \mathrm{kg})$, acepromazine $(1 \mathrm{mg} / \mathrm{kg})$, and xylazine $(25 \mathrm{mg} / \mathrm{kg})$ and two laser treatments were performed 1 week apart in order to achieve persistent IOP elevation. IOP was measured with a tonometer (TonoLab; Colonial Medical Supply, Franconia, NH). BMD (1 mg/kg/day) or vehicle phosphate-buffered saline (PBS) was administered systemically and continuously using an osmotic pump (Alzet; Durect, Cupertino, CA) inserted subcutaneously on the back of 16 animals per group. This concentration and mode of delivery was based on earlier results comparing $0.5 \mathrm{mg} / \mathrm{kg} /$ day vs. $1 \mathrm{mg} / \mathrm{kg} /$ day for efficacy in protecting RGC cell bodies during OHT [11]. Treatment began at the time of initial IOP elevation and continued for 8 weeks. Age-matched naïve control rats $(n=16)$ were also included for comparison.

\section{Cholera toxin $\beta$ injection and tissue preparation}

Forty-eight hours prior to sacrifice, rats were anesthetized with a mixture of ketamine $(50 \mathrm{mg} / \mathrm{kg})$ and xylazine $(25 \mathrm{mg} / \mathrm{kg})$ and eyes anesthetized locally using topical application of oxybuprocaine chlorhydrate [65]. The hypertensive eye received an intravitreal injection $(6 \mu \mathrm{l})$ of $0.5 \mathrm{mg}$ Cholera toxin subunit $\beta$ (CTB) conjugated to Alexa Fluor 594. (Molecular Probes, CA) while the control eye received a similar injection of CTB conjugated to Alexa Fluor 488 (Molecular Probes, CA) following earlier studies [21]. After the 48 hour period, animals were deeply anesthetized with a lethal intraperitoneal injection of sodium pentobarbital $(150 \mathrm{mg} / \mathrm{kg})$ and perfused intracardially with warm $\left(37^{\circ} \mathrm{C}\right)$ heparinized saline followed by $300 \mathrm{ml}$ of Zamboni's fixative at $4{ }^{\circ} \mathrm{C}$. Brains were cryoprotected overnight in $30 \%$ sucrose/PBS and $50 \mu \mathrm{m}$ coronal sections were taken through the midbrain and mounted on gelatin-coated slides. Retinas were dissected from the eye and vitreous removed after treatment with collagenase (400 units $/ \mathrm{ml}$ ) at $37^{\circ} \mathrm{C}$ for 15 minutes. Sections of optic nerve $2-3 \mathrm{~mm}$ proximal to the globe were isolated, post-fixed and prepared for embedding and semi-thin sectioning as previously described $[66,67]$.

\section{Retinal ganglion cell number and CTB uptake}

RGCs were immuno-labelled using antibodies against phosphorylated neurofilament-heavy (SMI31, Sternberger Monoclonal Incorporated, Baltimore, MD) following our published protocol [21]. Confocal images $\left(0.101 \mathrm{~mm}^{2}\right)$ were captured on an Olympus FV-1000 inverted confocal microscope along the midline of each retinal quadrant at 1 to $4 \mathrm{~mm}$ from the optic disc. The number of SMI31positive and CTB-positive RGCs per image were counted and RGC density calculated as cells per $\mathrm{mm}^{2}$.

\section{Axon quantification}

A 2- to 3-mm section of optic nerve proximal to the globe was isolated, post-fixed for 1 hour in $4 \%$ paraformaldehyde, and prepared for embedding and semithin sectioning [66]. Sections were stained with para-phenylenediamine (PPD) and then photographed using $100 \times$ oil-immersion and differential interference contrast optics. Photomicrographs of each optic nerve section were collected as a montage using an Olympus Provis AX70 microscope with motorized X-Y-Z stage and a digital CCD video camera. Each montage was contrast and edge-enhanced using the ImagePro software package (Media Cybernetics, CA). An additional routine was used to identify and count each axon in the montage 
for which a myelin sheath could be identified. We used this information to calculate the mean local axon density for each section of nerve. This was multiplied by the cross-sectional area of the nerve section to obtain an estimate of the total number of axons as described [66].

\section{Measurement of anterograde transport}

Alternate sections of the brain containing superior colliculus were photographed using a Spot-RT camera on an Olympus AX-70 upright microscope and intensity of label was quantified using ImagePro (Media Cybernetics, Bethesda, MD) as described previously [21]. After normalizing with respect to background, intensity was recorded based on mediolateral location in the section. Intensity calculations from alternate sections were then combined to form a colorimetric representation of CTB signal across the retinotopic collicular map. For each colliculus, we determined the fraction of intact retinotopic map, defined as the percent area with CTB signal $\geq 70 \%$ maximum.

\section{Statistical analysis}

Unless otherwise indicated, all data are presented as the mean \pm the standard error of the mean (SEM). SigmaPlot for Windows version 11.0 (Systat Software, Inc,; Chicago, IL) was used to calculate p values in comparing data using either ANOVA or $\mathrm{t}$ tests for data meeting criteria for normalcy or using non-parametric rank statistics for data failing normalcy.

\section{List of abbreviations}

BMD: brimonidine; CTB: cholera toxin subunit $\beta$; CAMP: cyclic adenosine monophosphate; GSK3: glycogen synthase kinase-3; IOP; intraocular pressure; NMDA: N-methyl-D-aspartic acid; OHT: ocular hypertension; PI3K: phosphatidylinositol 3 kinase; RGCs: retinal ganglion cells.

\section{Acknowledgements \\ Funding provided by an Allergan, Inc. Discovery Research Grant (DJC), the American Health Assistance Foundation (DJC), the Melza M. and Frank Theodore Barr Foundation through the Glaucoma Research Foundation (DJC), NIH EY017427 (DJC), and an Unrestricted Grant from Research to Prevent Blindness to the Vanderbilt University School of Medicine Department of Ophthalmology and Visual Sciences. Imaging supported through the Vanderbilt University Medical Center Cell Imaging Shared Resource core facility (CTSA grant UL1 RR024975 from NCRR/NIH) and the Vanderbilt Vision Research Center (P30EY008126).}

\section{Author details}

${ }^{1}$ The Vanderbilt Eye Institute, Vanderbilt University Medical Center, Nashville, TN 37205, USA. ªllergan, Inc., Irvine, CA 92623, USA.

\section{Authors' contributions}

WSL carried out the retinal immunocytochemistry, cell counts, statistical analysis, and helped to draft the manuscript. LR carried out the IOP elevation, BMD delivery, CTB intravitreal injections and tissue acquisition. SDC carried out the anterograde transport measurements, statistical analysis and helped to draft the manuscript.

LAW conceived of the study, and participated in its design and coordination. DJC participated in the study design, coordination and analysis and oversaw the preparation of the manuscript. All authors read and approved the final manuscript.

\section{Competing interests}

WSL, SDC and DJC received funding from Allergan Inc. (Discovery Research Grant to DJC) for these studies. LR and LAW were employed by Allergan Inc during these studies. All experimental procedures were approved by the Vanderbilt University Medical Center Institutional Animal Care and Use Committee.

Received: 26 October 2010 Accepted: 13 January 2011

Published: 13 January 2011

\section{References}

1. Nickells RW: From ocular hypertension to ganglion cell death: a theoretical sequence of events leading to glaucoma. Can J Ophthalmol 2007, 42:278-287.

2. Quigley HA: Neuronal death in glaucoma. Prog Retin Eye Res 1999, 18:39-57.

3. Heijl A, Leske MC, Bengtsson B, Hyman L, Hussein M: Reduction of intraocular pressure and glaucoma progression: results from the Early Manifest Glaucoma Trial. Arch Ophthalmol 2002, 120:1268-1279.

4. Investigators TA: The Advanced Glaucoma Intervention Study (AGIS): 7. The relationship between control of intraocular pressure and visual field deterioration.The AGIS Investigators. Am J Ophthalmol 2000, 130:429-440.

5. Cheung W, Guo L, Cordeiro MF: Neuroprotection in glaucoma: drugbased approaches. Optom Vis Sci 2008, 85:406-416.

6. Schober MS, Chidlow G, Wood JP, Casson RJ: Bioenergetic-based neuroprotection and glaucoma. Clin Experiment Ophthalmol 2008, 36:377-385.

7. Ogidigben $\mathrm{M}$, Chu TC, Potter DE: Alpha-2 adrenoceptor mediated changes in aqueous dynamics: effect of pertussis toxin. Exp Eye Res 1994, 58:729-736.

8. Toris CB, Camras CB, Yablonski ME: Acute versus chronic effects of brimonidine on aqueous humor dynamics in ocular hypertensive patients. Am J Ophthalmol 1999, 128:8-14.

9. Yoles E, Wheeler LA, Schwartz M: Alpha2-adrenoreceptor agonists are neuroprotective in a rat model of optic nerve degeneration. Invest Ophthalmol Vis Sci 1999, 40:65-73.

10. Vidal-Sanz M, Lafuente MP, Mayor S, de Imperial JM, Villegas-Perez MP: Retinal ganglion cell death induced by retinal ischemia: neuroprotective effects of two alpha-2 agonists. Surv Ophthalmol 2001, 45(Suppl 3): S261-267, discussion S273-266.

11. WoldeMussie E, Ruiz G, Wijono M, Wheeler LA: Neuroprotection of retinal ganglion cells by brimonidine in rats with laser-induced chronic ocular hypertension. Invest Ophthalmol Vis Sci 2001, 42:2849-2855.

12. Hernandez M, Urcola JH, Vecino E: Retinal ganglion cell neuroprotection in a rat model of glaucoma following brimonidine, latanoprost or combined treatments. Exp Eye Res 2008, 86:798-806.

13. Ma K, Xu L, Zhang H, Zhang S, Pu M, Jonas JB: Effect of brimonidine on retinal ganglion cell survival in an optic nerve crush model. Am J Ophthalmol 2009, 147:326-331.

14. Gao H, Qiao X, Cantor LB, WuDunn D: Up-regulation of brain-derived neurotrophic factor expression by brimonidine in rat retinal ganglion cells. Arch Ophthalmol 2002, 120:797-803.

15. Dong CJ, Guo Y, Wheeler L, Hare WA: Alpha2 adrenergic receptormediated modulation of cytosolic Ca++ signals at the inner plexiform layer of the rat retina. Invest Ophthalmol Vis Sci 2007, 48:1410-1415.

16. Dong CJ, Guo Y, Agey P, Wheeler L, Hare WA: Alpha2 adrenergic modulation of NMDA receptor function as a major mechanism of RGC protection in experimental glaucoma and retinal excitotoxicity. Invest Ophthalmol Vis Sci 2008, 49:4515-4522.

17. Galanopoulos A, Goldberg I: Clinical efficacy and neuroprotective effects of brimonidine in the management of glaucoma and ocular hypertension. Clin Ophthalmol 2009, 3:117-122.

18. Aviles-Trigueros M, Mayor-Torroglosa S, Garcia-Aviles A, Lafuente MP, Rodriguez ME, Miralles de Imperial J, Villegas-Perez MP, Vidal-Sanz M: Transient ischemia of the retina results in massive degeneration of the retinotectal projection: long-term neuroprotection with brimonidine. Exp Neurol 2003, 184:767-777.

19. Whitmore AV, Libby RT, John SW: Glaucoma: thinking in new ways-a role for autonomous axonal self-destruction and other compartmentalised processes? Prog Retin Eye Res 2005, 24:639-662. 
20. Buckingham BP, Inman DM, Lambert W, Oglesby E, Calkins DJ, Steele MR, Vetter ML, Marsh-Armstrong N, Horner PJ: Progressive ganglion cell degeneration precedes neuronal loss in a mouse model of glaucoma. J Neurosci 2008, 28:2735-2744.

21. Crish SD, Sappington RM, Inman DM, Horner PJ, Calkins DJ: Distal axonopathy with structural persistence in glaucomatous neurodegeneration. Proc Natl Acad Sci USA 2010, 107:5196-5201.

22. Jakobs TC, Libby RT, Ben Y, John SW, Masland RH: Retinal ganglion cell degeneration is topological but not cell type specific in DBA/2J mice. J Cell Biol 2005, 171:313-325.

23. Schlamp CL, Li Y, Dietz JA, Janssen KT, Nickells RW: Progressive ganglion cell loss and optic nerve degeneration in DBA/2J mice is variable and asymmetric. BMC Neurosci 2006, 7:66.

24. Soto I, Oglesby E, Buckingham BP, Son JL, Roberson ED, Steele MR, Inman DM, Vetter ML, Horner PJ, Marsh-Armstrong N: Retinal ganglion cells downregulate gene expression and lose their axons within the optic nerve head in a mouse glaucoma model. J Neurosci 2008, 28:548-561.

25. Wax MB, Tezel G, Yang J, Peng G, Patil RV, Agarwal N, Sappington RM, Calkins DJ: Induced autoimmunity to heat shock proteins elicits glaucomatous loss of retinal ganglion cell neurons via activated T-cellderived fas-ligand. J Neurosci 2008, 28:12085-12096.

26. Danias J, Shen F, Goldblum D, Chen B, Ramos-Esteban J, Podos SM, Mittag T: Cytoarchitecture of the retinal ganglion cells in the rat. Invest Ophthalmol Vis Sci 2002, 43:587-594.

27. Siminoff $R$, Schwassmann HO, Kruger $L$ : An electrophysiological study of the visual projection to the superior colliculus of the rat. J Comp Neurol 1966, 127:435-444

28. Drager UC, Hubel DH: Topography of visual and somatosensory projections to mouse superior colliculus. J Neurophysiol 1976, 39:91-101.

29. Lei Y, Garrahan N, Hermann B, Fautsch MP, Johnson DH, Hernandez MR, Boulton M, Morgan JE: Topography of neuron loss in the retinal ganglion cell layer in human glaucoma. Br J Ophthalmol 2009, 93:1676-1679.

30. Soto I, Pease ME, Son JL, Shi X, Quigley HA, Marsh-Armstrong N: Retinal Ganglion Cell Loss in a Rat Ocular Hypertension Model is Sectorial and Involves Early Optic Nerve Axon Loss. Invest Ophthalmol Vis Sci 2010, 10-5856, iovs.

31. Danylkova NO, Alcala SR, Pomeranz HD, McLoon LK: Neuroprotective effects of brimonidine treatment in a rodent model of ischemic optic neuropathy. Exp Eye Res 2007, 84:293-301.

32. Mayor-Torroglosa S, De la Villa P, Rodriguez ME, Lopez-Herrera MP, AvilesTrigueros M, Garcia-Aviles A, de Imperial JM, Villegas-Perez MP, VidalSanz M: Ischemia results 3 months later in altered ERG, degeneration of inner layers, and deafferented tectum: neuroprotection with brimonidine. Invest Ophthalmol Vis Sci 2005, 46:3825-3835.

33. Ahmed FA, Hegazy K, Chaudhary P, Sharma SC: Neuroprotective effect of alpha(2) agonist (brimonidine) on adult rat retinal ganglion cells after increased intraocular pressure. Brain Res 2001, 913:133-139.

34. Wheeler LA, Gil DW, WoldeMussie E: Role of alpha-2 adrenergic receptors in neuroprotection and glaucoma. Surv Ophthalmol 2001, 45(Suppl 3): S290-294, discussion S295-296.

35. Kalapesi FB, Coroneo MT, Hill MA: Human ganglion cells express the alpha-2 adrenergic receptor: relevance to neuroprotection. $\mathrm{Br} J$ Ophthalmol 2005, 89:758-763.

36. Woldemussie $E$, Wijono M, Pow D: Localization of alpha 2 receptors in ocular tissues. Vis Neurosci 2007, 24:745-756.

37. Vidal L, Diaz F, Villena A, Moreno M, Campos JG, Perez de Vargas I: Reaction of Muller cells in an experimental rat model of increased intraocular pressure following timolol, latanoprost and brimonidine. Brain Res Bull 2010, 82:18-24.

38. Knels L, Worm M, Wendel M, Roehlecke C, Kniep E, Funk RH: Effects of advanced glycation end products-inductor glyoxal and hydrogen peroxide as oxidative stress factors on rat retinal organ cultures and neuroprotection by UK-14,304. J Neurochem 2008, 106:1876-1887.

39. Ozdemir G, Tolun Fl, Gul M, Imrek S: Retinal oxidative stress induced by intraocular hypertension in rats may be ameliorated by brimonidine treatment and N-acetyl cysteine supplementation. J Glaucoma 2009, 18:662-665.

40. Tatton WG, Chalmers-Redman RM, Sud A, Podos SM, Mittag TW: Maintaining mitochondrial membrane impermeability. an opportunity for new therapy in glaucoma? Surv Ophthalmol 2001, 45(Suppl 3): S277-283, discussuin S295-276.

41. Aktas Z, Gurelik G, Akyurek N, Onol M, Hasanreisoglu B: Neuroprotective effect of topically applied brimonidine tartrate $0.2 \%$ in endothelin-1induced optic nerve ischaemia model. Clin Experiment Ophthalmol 2007, 35:527-534.

42. Lai RK, Chun T, Hasson D, Lee S, Mehrbod F, Wheeler L: Alpha-2 adrenoceptor agonist protects retinal function after acute retinal ischemic injury in the rat. Vis Neurosci 2002, 19:175-185.

43. Baptiste DC, Hartwick AT, Jollimore CA, Baldridge WH, Chauhan BC, Tremblay F, Kelly ME: Comparison of the neuroprotective effects of adrenoceptor drugs in retinal cell culture and intact retina. Invest Ophthalmol Vis Sci 2002, 43:2666-2676.

44. Taraviras S, Olli-Lahdesmaki T, Lymperopoulos A, Charitonidou D, Mavroidis M, Kallio J, Scheinin M, Flordellis C: Subtype-specific neuronal differentiation of PC12 cells transfected with alpha2-adrenergic receptors. Eur J Cell Biol 2002, 81:363-374.

45. Tolbert LM, Russell DS, Duman RS: Norepinephrine activates extracellularregulated kinase in cortical neurons. Biol Psychiatry 2003, 54:983-993.

46. Klocker N, Kermer P, Weishaupt JH, Labes M, Ankerhold R, Bahr M: Brainderived neurotrophic factor-mediated neuroprotection of adult rat retinal ganglion cells in vivo does not exclusively depend on phosphatidyl-inositol-3'-kinase/protein kinase B signaling. J Neurosci 2000, 20:6962-6967.

47. Nakazawa T, Shimura M, Tomita H, Akiyama H, Yoshioka Y, Kudou H, Tamai M: Intrinsic activation of PI3K/Akt signaling pathway and its neuroprotective effect against retinal injury. Curr Eye Res 2003, 26:55-63.

48. Maggirwar SB, Sarmiere PD, Dewhurst S, Freeman RS: Nerve growth factordependent activation of NF-kappaB contributes to survival of sympathetic neurons. J Neurosci 1998, 18:10356-10365.

49. Biggs WH, Meisenhelder J, Hunter T, Cavenee WK, Arden KC: Protein kinase B/Akt-mediated phosphorylation promotes nuclear exclusion of the winged helix transcription factor FKHR1. Proc Natl Acad Sci USA 1999, 96:7421-7426.

50. Brunet A, Bonni A, Zigmond MJ, Lin MZ, Juo P, Hu LS, Anderson MJ, Arden KC, Blenis J, Greenberg ME: Akt promotes cell survival by phosphorylating and inhibiting a Forkhead transcription factor. Cell 1999, 96:857-868.

51. Datta SR, Dudek H, Tao X, Masters S, Fu H, Gotoh Y, Greenberg ME: Akt phosphorylation of BAD couples survival signals to the cell-intrinsic death machinery. Cell 1997, 91:231-241.

52. del Peso L, Gonzalez-Garcia M, Page C, Herrera R, Nunez G: Interleukin-3induced phosphorylation of BAD through the protein kinase Akt. Science 1997, 278:687-689.

53. Vander Heiden MG, Chandel NS, Li XX, Schumacker PT, Colombini M, Thompson CB: Outer mitochondrial membrane permeability can regulate coupled respiration and cell survival. Proc Natl Acad Sci USA 2000, 97:4666-4671.

54. Zhou H, Li XM, Meinkoth J, Pittman RN: Akt regulates cell survival and apoptosis at a postmitochondrial level. J Cell Biol 2000, 151:483-494

55. Goold RG, Owen R, Gordon-Weeks PR: Glycogen synthase kinase 3beta phosphorylation of microtubule-associated protein $1 \mathrm{~B}$ regulates the stability of microtubules in growth cones. J Cell Sci 1999, 112(Pt 19):3373-3384

56. Fukata $Y$, Itoh TJ, Kimura T, Menager $C$, Nishimura T, Shiromizu T, Watanabe $\mathrm{H}$, Inagaki N, Iwamatsu A, Hotani $\mathrm{H}$, Kaibuchi K: CRMP-2 binds to tubulin heterodimers to promote microtubule assembly. Nat Cell Biol 2002, 4:583-591.

57. Kawano Y, Yoshimura T, Tsuboi D, Kawabata S, Kaneko-Kawano T, Shirataki H, Takenawa T, Kaibuchi K: CRMP-2 is involved in kinesin-1dependent transport of the Sra-1/WAVE1 complex and axon formation. Mol Cell Biol 2005, 25:9920-9935.

58. Kimura T, Watanabe H, Iwamatsu A, Kaibuchi K: Tubulin and CRMP-2 complex is transported via Kinesin-1. J Neurochem 2005, 93:1371-1382.

59. Bajaj NP, Miller CC: Phosphorylation of neurofilament heavy-chain sidearm fragments by cyclin-dependent kinase- 5 and glycogen synthase kinase-3alpha in transfected cells. J Neurochem 1997, 69:737-743.

60. Jung C, Lee S, Ortiz D, Zhu Q, Julien JP, Shea TB: The high and middle molecular weight neurofilament subunits regulate the association of neurofilaments with kinesin: inhibition by phosphorylation of the high molecular weight subunit. Brain Res Mol Brain Res 2005, 141:151-155. 
61. Cosker KE, Eickholt BJ: Phosphoinositide 3-kinase signalling events controlling axonal morphogenesis. Biochem Soc Trans 2007, 35:207-210.

62. Grimes CA, Jope RS: The multifaceted roles of glycogen synthase kinase 3beta in cellular signaling. Prog Neurobiol 2001, 65:391-426.

63. Hannigan G, Troussard AA, Dedhar S: Integrin-linked kinase: a cancer therapeutic target unique among its ILK. Nat Rev Cancer 2005, 5:51-63.

64. Acheampong AA, Shackleton M, John B, Burke J, Wheeler L, Tang-Liu D: Distribution of brimonidine into anterior and posterior tissues of monkey, rabbit, and rat eyes. Drug Metab Dispos 2002, 30(4):421-9.

65. Drouyer E, Dkhissi-Benyahya O, Chiquet C, WoldeMussie E, Ruiz G, Wheeler LA, Denis P, Cooper HM: Glaucoma alters the circadian timing system. PLoS One 2008, 3:e3931.

66. Inman DM, Sappington RM, Horner PJ, Calkins DJ: Quantitative correlation of optic nerve pathology with ocular pressure and corneal thickness in the DBA/2 mouse model of glaucoma. Invest Ophthalmol Vis Sci 2006, 47:986-996.

67. Sappington RM, Carlson BJ, Crish SD, Calkins DJ: The microbead occlusion model: a paradigm for induced ocular hypertension in rats and mice. Invest Ophthalmol Vis Sci 2010, 51:207-216.

doi:10.1186/1750-1326-6-4

Cite this article as: Lambert et al: Brimonidine prevents axonal and somatic degeneration of retinal ganglion cell neurons. Molecular

Neurodegeneration 2011 6:4.

\section{Submit your next manuscript to BioMed Central} and take full advantage of:

- Convenient online submission

- Thorough peer review

- No space constraints or color figure charges

- Immediate publication on acceptance

- Inclusion in PubMed, CAS, Scopus and Google Scholar

- Research which is freely available for redistribution

Submit your manuscript at www.biomedcentral.com/submit 